\title{
Methane production from in vitro incubation of kikuyu grass, lucerne and forages containing condensed tannins
}

\author{
M.H. TAVENDALE ${ }^{1}$, L.P. MEAGHER ${ }^{1}$, Z.A. PARK-NG ${ }^{1}$, G.C. WAGHORN ${ }^{2}$ and G.T. ATTWOOD ${ }^{1}$ \\ ${ }^{1}$ AgResearch, Grasslands Research Centre, PB 11008, Palmerston North \\ ${ }^{2}$ Dexcel, PB 3221, Hamilton \\ lucy.meagher@agresearch.co.nz
}

\begin{abstract}
A series of in vitro incubations with kikuyu grass (Pennisetum clandestinum), lucerne and six legumes containing condensed tannins (CT) were undertaken to evaluate this technique against in vivo trials in New Zealand, measuring methane emissions. Published trials have demonstrated a reduction in methane emissions associated with CT and in one instance from kikuyu. The incubations used fresh minced forage (equivalent to $0.5 \mathrm{~g}$ dry matter (DM)) and were carried out in $50 \mathrm{ml}$ sealed bottles containing buffer and rumen inoculum. Gas was sampled through a septum to monitor volume and composition throughout the $24 \mathrm{~h}$ incubation. Incubation for $24 \mathrm{~h}$ resulted in $2.4-6.6 \%$ conversion of DM to methane, and suggested CT concentrations below about $8 \%$ of the $\mathrm{DM}$ can reduce methane production without inhibiting fermentation rate. Higher concentrations of CT $(>8 \%)$ were associated with a lower rate of digestion. In common with in vivo trials, $\mathrm{CT}$ concentration in forage $\mathrm{DM}$ was inversely related to methane (adjusted $\mathrm{R}^{2}=0.49 ; \mathrm{P}=0.01$ ) and volatile fatty acid (adjusted $\mathrm{R}^{2}=0.86 ; \mathrm{P}<0.001$ ) production. Ash concentration in forage DM was proportionally related to methane (adjusted $\mathrm{R}^{2}=0.56 ; \mathrm{P}=0.005$ ).
\end{abstract}

Keywords: ash, condensed tannins, in vitro incubation, methane, rumen

\section{Introduction}

Methane losses from ruminant digestion account for about $33 \%$ of NZ's greenhouse gas (GHG) emissions, $6-7 \%$ of feed energy eaten, or $9-10 \%$ of metabolisable energy (ME) intake. This represents a loss of feed energy that could otherwise contribute to production.

When methane emissions are expressed as $\mathrm{g} \mathrm{CH}_{4} / \mathrm{kg}$ dry matter intake (DMI), animal trials have shown condensed tannins (CT) in Lotus species are able to reduce methane losses by about $15 \%$ in sheep (Waghom et al. 2002) and cattle (Woodward et al. 2004). Larger reductions have been reported in sheep and cows grazing kikuyu (Pennisetum clandestinum) dominant pasture during autumn, but not during summer (Ulyatt $e t$ al. 2002). In general legumes result in lower emissions than grasses (Waghorn et al. 2002; O'Hara et al. 2003), although attempts to relate actual emissions with forage composition or digestibility (Johnson and Johnson,
1995) have not produced conclusive relationships.

Animal trials to measure methane are time consuming and expensive. Methane is most often measured using marker dilution with sulphur hexafluoride ( $\mathrm{SF}_{6}$ ), which is an inert gas released at a known rate from a 'permeation tube' placed in the rumen (Lassey et al. 2001). Of equal importance to methane emissions is an accurate measurement of feed intake. This is difficult in grazing animals, so many measurements of methane production are made with animals housed in doors to enable individual feeding (Waghorn et al. 2002). Other techniques include indirect calorimetry, which requires measurement of air flow and composition, usually by placing animals in a sealed respiration calorimeter. This technique is suitable for small numbers of animals, is expensive and also restricts animal behaviour.

The importance of methane emissions for global warming, lost feed energy and the considerable expense of animal trials, provide an incentive for alternative techniques to screen forage diets to identify those having low methanogenic potential. The data presented here have been derived from a fresh minced forage preparation that resembled chewed material (Barrell et al. 2000), and include measurements of gas production and composition, to evaluate this in vitro technique against in vivo trials in NZ measuring methane emissions. Ten forage samples were incubated in vitro to evaluate repeatability between replicates and to compare methane measurements with published in vivo data from sheep and cattle fed kikuyu $(\mathrm{Ku})$, lucerne (Medicago sativa, Lu), Lotus spp. and sulla (Hedysarum coronarium, $\mathrm{Hc}$ ).

\section{Materials and methods}

Lucerne $(\mathrm{Lu})$, kikuyu grasses $(\mathrm{Ku}$; two samples harvested in Northland during the in vivo trials of Ulyatt et al. (2002) and one sample from Grasslands Research Centre, Palmerston North), four Lotus species (corniculatus, Lc; corniculatus rhizomatus, Lr; pedunculatus, Lp; tenuis, Lt), Hc (two samples, harvested in different seasons) and erect dorycnium (Dorycnium rectum, Dr) were incubated in vitro. The forages were harvested between 1100 and $1400 \mathrm{~h}$ and placed on ice then transferred to a freezer at $-18^{\circ} \mathrm{C}$ for storage. All forages were separated into leaf and stem 
fractions and only the leaf fractions were used in the incubations. The preparation and incubation of forages has been described by Barrell et al. (2000). The cysteine hydrochloride reducing agent used by Barrell et al. (2000) was not included in the incubations because of possible methanogenic inhibition. Fresh minced forage samples $(0.5 \mathrm{~g}$ DM equivalent) were incubated with buffered rumen inoculum $(5 \times$ replication $)$ and gas production (methane and hydrogen) measured (by gas chromatography) over $24 \mathrm{~h}$ according to the method described by Tavendale et al. (2005). The rumen inoculum added to each bottle $(3 \mathrm{ml})$ was a composite obtained from four fistulated sheep grazing ryegrass pasture. Lucerne was incubated as a reference forage during the three incubations. Data presented here have been generated from incubated leaf, which compared to stem (data not shown), contains higher concentrations of crude protein (CP), non-structural carbohydrates (NSC) and CT.

The incubations were carried out over three days as follows. A total of 65 incubation bottles were prepared: 5 from each forage sample, except for lucerne where three sets of 5 bottles were prepared and used as a reference forage on each of the three incubation days. All 5 bottles from each forage sample were incubated on the same day, and each bottle represents a replicate.

Measurements included gas production at approximately $2 \mathrm{~h}$ intervals over the first $12 \mathrm{~h}$ of incubation and at the conclusion at $24 \mathrm{~h}$. Head space gas was analysed to determine concentrations of methane and hydrogen by gas chromatography according to Tavendale et al. (2005). At the conclusion of incubations (24h), subsamples of rumen liquor were taken to deter mine concentrations of volatile fatty acids (VFA) according to the method of Attwood et al. (1998).

Forage composition was estimated by near infrared reflectance spectroscopy (Corson et al. 1999) and concentrations of $\mathrm{CT}$ by the butanol - $\mathrm{HCl}$ extraction method described by Terrill et al. (1992). The gross energy (GE) concentrations in the forages were calculated from feed composition, enabling methane production to be expressed in terms of forage GE content.

Data are presented to show the percentage of methane in the gases of fermentation. Gas production includes that from DM digestion and carbon dioxide $\left(\mathrm{CO}_{2}\right)$ released from the buffer as a consequence of declining $\mathrm{pH}$, in response to VFA production. Carbon dioxide release from the buffer was measured in a separate set of bottles over a series of $\mathrm{pH}$ values (6.8 to 5.4) by addition of acetic acid to sealed bottles containing $12 \mathrm{ml}$ of saturated buffer solution and relating $\mathrm{CO}_{2}$ volumes to $\mathrm{pH}$ of the solution. The amounts of $\mathrm{CO}_{2}$ from buffer were subtracted from measured gas volumes, on the basis of media $\mathrm{pH}$ at collection, enabling methane to be expressed in terms of gases from fermentation. The presence of significant concentrations of hydrogen may indicate the presence of oxygen, and the inhibition of methanogenesis. Hydrogen concentrations exceeded $2 \%$ in nine of the 65 bottles $(2 \mathrm{Hc}, 5 \mathrm{Lu}, 1 \mathrm{Ku}, 1 \mathrm{Lc})$ so these data were not included in the analyses.

The accumulated methane, percent methane, and the total volume of gas produced were analysed using Residual Maximum Likelihood analysis (REML) in GenStat v8.0 (2005). REML allows sources of variation to be included as follows: (a) the day of incubation; (b) the forages; and (c) the replicates. Forages and time and their interaction were fitted as fixed effects. An autoregressive model with an order of 1 (AR1) model was fitted to model the correlation between gas measurement times. In order to make the variance homogeneous as required for a REML analysis, the data was square-root transformed. The relationships between CT concentrations, VFA yield or $\mathrm{pH}$ and methane production were analysed using linear regression, as was the relationship between CT concentration and VFA yield. Multiple regression was used to determine which chemical variables were the best predictors of the amount of methane produced.

\section{Results}

The legume leaves contained over $21 \% \mathrm{CP}$ in the DM, less than $20 \% \mathrm{NDF}$ (neutral detergent fibre) (except for $\mathrm{Lu}$ ) so the majority of the DM (Table 1) should have been highly digestible, unless affected by the CT concentration. The kikuyu had a lower CP and much higher fibre concentrations than the legumes. The concentration of CT in the DM of forages, other than $\mathrm{Lu}$ and $\mathrm{Ku}$, ranged from 1.6 to $18.6 \%$ of the DM (Table 1). When concentrations of CT exceeded 3.3\% of the DM, the majority was not bound with forage protein or fibre and was free to bind with components of the in vitro incubation.

Incubations of $0.5 \mathrm{~g}$ DM yielded $80-108 \mathrm{ml}$ of gas after $12 \mathrm{~h}$ of incubation and a further $4-12 \mathrm{ml}$ between 13 and $24 \mathrm{~h}$ (Figure 1). However at $24 \mathrm{~h}$, between 11 and $26 \mathrm{ml}$ of the gas was derived from non-fermentation $\mathrm{CO}_{2}$ (Table 2), released from the buffer as the $\mathrm{pH}$ declined over the incubation. The average methane concentration in gases from fermentation ranged from $7 \%(\mathrm{Lp}, \mathrm{Lr})$ to $16 \%(\mathrm{Lu})$ at $24 \mathrm{~h}$.

The rate of methane production over the $24 \mathrm{~h}$ in vitro incubation varied amongst feed types, with very rapid initial rates of production from $\mathrm{Lu}$ and $\mathrm{Hc}$, decreasing after 12h (Figure 1). Kikuyu had a slow initial rate of methane production, after which it increased rapidly to achieve a yield similar to $\mathrm{Hc}$ at $24 \mathrm{~h}$. Rates and total methane production were lowest for $\mathrm{Lp}$, Lr and Dr, with 
Table 1 Chemical composition of forages used for in vitro incubations. Data are g/100 g DM. Rhiz. refers to rhizomatous strain of $L$. corniculatus.

\begin{tabular}{|c|c|c|c|c|c|c|c|c|}
\hline \multirow{2}{*}{ Species } & \multicolumn{2}{|c|}{ Condensed tannin } & \multirow{2}{*}{$\mathrm{CP}$} & \multirow{2}{*}{ Lipid } & \multirow{2}{*}{ Ash } & \multirow{2}{*}{ NDF } & \multirow{2}{*}{ NSC } & \multirow{2}{*}{$\begin{array}{c}\mathrm{GE} \\
\mathrm{MJ} / \mathrm{kg} \mathrm{DM}\end{array}$} \\
\hline & Total & Unbound & & & & & & \\
\hline \multicolumn{9}{|l|}{ Lotus } \\
\hline pedunculatus & 11.2 & 8.6 & 21.5 & 4.4 & 6.9 & 16.1 & 39.9 & 18.4 \\
\hline cornic. rhiz*. & 9.6 & 7.5 & 21.1 & 4.5 & 6.6 & 17.0 & 41.2 & 18.4 \\
\hline corniculatus & 3.3 & 1.7 & 28.2 & 4.5 & 7.4 & 15.1 & 41.5 & 18.7 \\
\hline tenuis & 1.6 & 0.4 & 22.3 & 4.6 & 8 & 19.2 & 44.3 & 18.3 \\
\hline Sulla & 6.6 & 4.8 & 25.2 & 3.3 & 11.7 & 15.6 & 37.6 & 17.5 \\
\hline D. rectum & 18.6 & 15.2 & 21.3 & 3.7 & 6.9 & 11.8 & 37.4 & 18.2 \\
\hline Kikuyu & 0 & 0 & 20.7 & 3.6 & 11.5 & 44.7 & 19.5 & 17.3 \\
\hline Lucerne & 0 & 0 & 24.3 & 3.3 & 10.3 & 31.2 & 30.9 & 17.7 \\
\hline
\end{tabular}

Figure 1 Cumulative gas $(\mathrm{A})$ and methane $(\mathrm{B})$ production $(\mathrm{ml})$ from $0.5 \mathrm{~g}$ DM over $24 \mathrm{~h}$ from fresh forages incubated in vitro. Abbreviations see text.
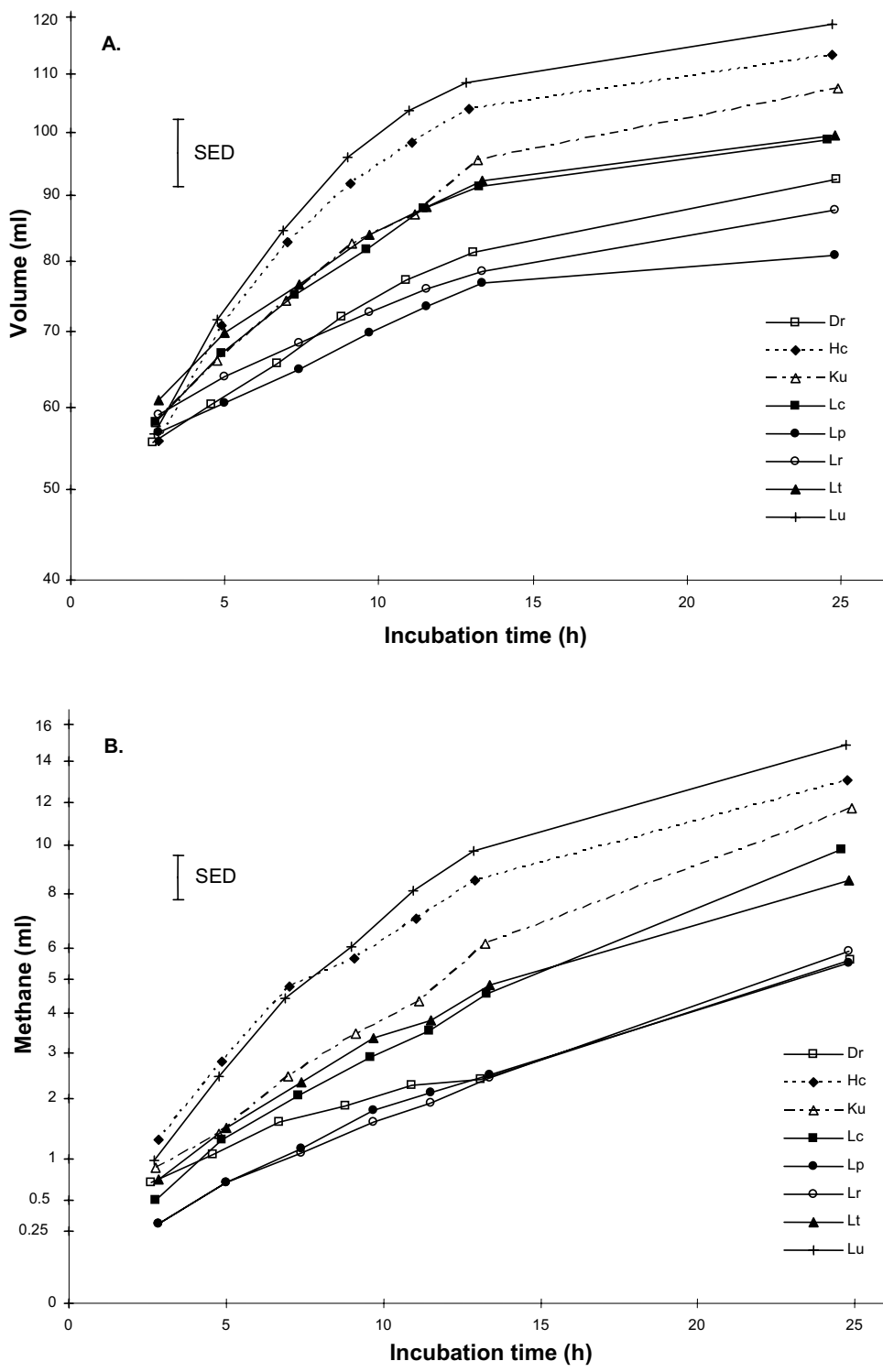
Table 2 Total methane produced from in vitro incubation of $0.5 \mathrm{~g}$ forage DM after 3,13 and $24 \mathrm{~h}$ of incubation, with $\mathrm{pH}$ and carbon dioxide emissions at $24 \mathrm{~h}$. The approximate least significant difference (LSD) for the total methane data is calculated using the average standard error of difference and 2.89 degrees of freedom (as estimated by REML). As the total methane data required square-root transforming, the LSD relates to this. Back-transformed values on the original scale are also given in parentheses.

\begin{tabular}{|c|c|c|c|c|c|c|c|}
\hline \multirow[t]{2}{*}{ Species } & \multicolumn{3}{|c|}{ - Cumulative methane $(\mathrm{ml})$} & \multirow[b]{2}{*}{$\mathrm{pH}$} & \multicolumn{3}{|c|}{$24 \mathrm{~h}$} \\
\hline & $3 \mathrm{~h}$ & $13 \mathrm{~h}$ & $24 \mathrm{~h}$ & & $\begin{array}{c}\mathrm{ml} \mathrm{CO}_{2} \\
\text { buffer }(\mathrm{ml})\end{array}$ & $\begin{array}{l}\text { from } \\
\text { forage }\end{array}$ & $\begin{array}{c}\% \mathrm{CH}_{4} \text { in } \\
\text { ferment gas }\end{array}$ \\
\hline \multicolumn{8}{|l|}{ Lotus } \\
\hline pedunculatus & $0.6(0.3)$ & $1.6(2.5)$ & $2.4(5.5)$ & 6.4 & 11.0 & 69.0 & 8.0 \\
\hline cornic. rhiz. & $0.5(0.3)$ & $1.6(2.4)$ & $2.4(5.9)$ & 6.4 & 10.3 & 76.3 & 7.7 \\
\hline corniculatus & $0.7(0.5)$ & $2.1(4.6)$ & $3.1(9.8)$ & 6.1 & 21.7 & 72.6 & 13.5 \\
\hline tenuis & $0.9(0.7)$ & $2.2(4.8)$ & $2.9(8.5)$ & 6.3 & 13.6 & 82.8 & 10.3 \\
\hline Sulla & $1.1(1.3)$ & $2.9(8.5)$ & $3.6(13.0)$ & 5.9 & 25.0 & 75.3 & 17.5 \\
\hline D. rectum & $0.8(0.7)$ & $1.5(2.4)$ & $2.4(5.6)$ & 6.2 & 19.7 & 67.6 & 8.5 \\
\hline Kikuyu & $0.9(0.9)$ & $2.5(6.2)$ & $3.4(11.7)$ & 6.1 & 18.4 & 79.5 & 14.9 \\
\hline Lucerne & $1.0(1.0)$ & $3.1(9.7)$ & $3.9(14.9)$ & 5.8 & 26.3 & 77.2 & 19.3 \\
\hline Approximate LSD & 1.0 & 1.0 & 1.0 & & & & \\
\hline
\end{tabular}

Figure 2 Methane yield ( $\mathrm{ml} / 24 \mathrm{~h} / 0.5 \mathrm{~g} \mathrm{DM})$ and CT concentrations in the DM of fresh forages incubated in vitro. Abbreviations see text.

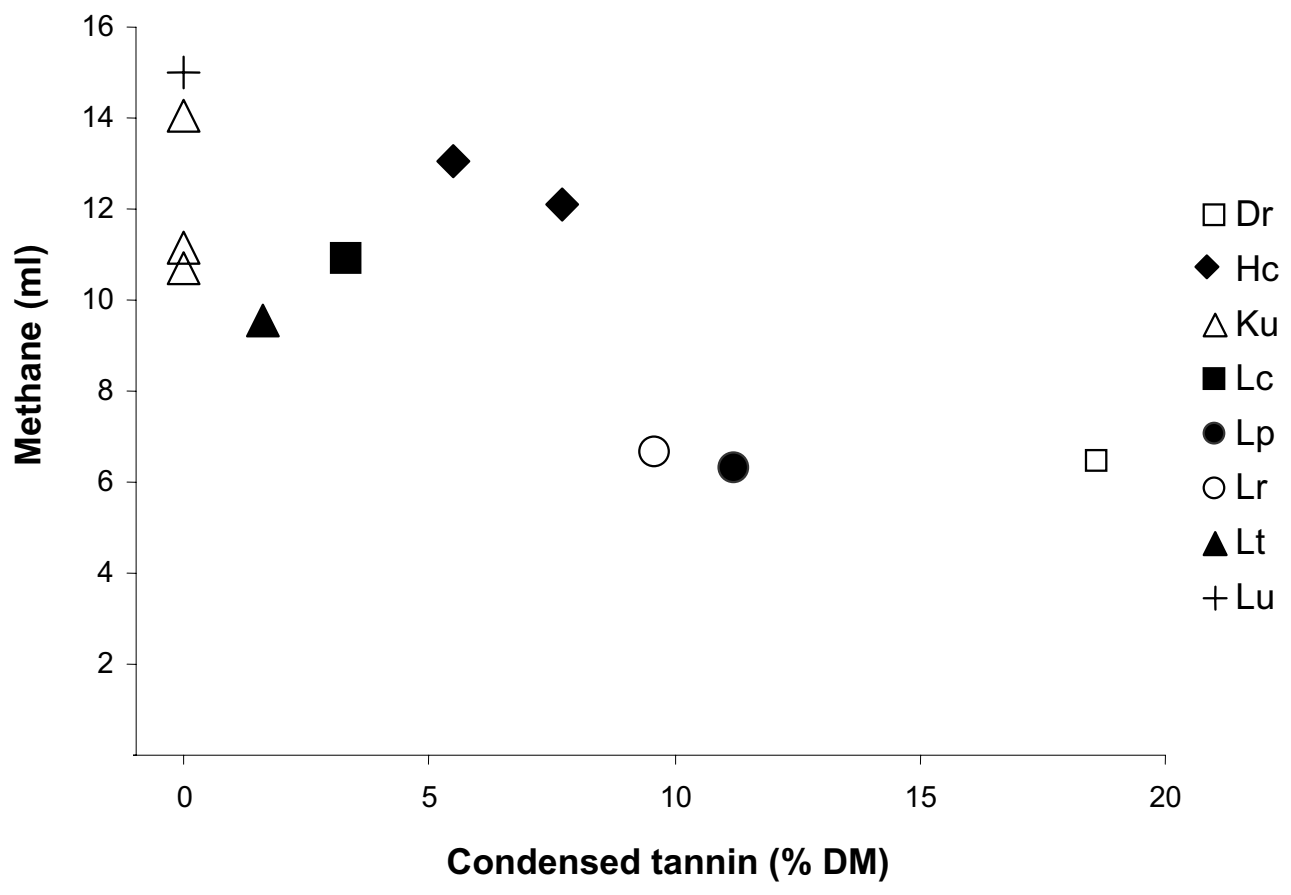

total yields less than half that for $\mathrm{Lu}, \mathrm{Ku}$ and $\mathrm{Hc}$ (Table 2 , Figure 1). Hourly methane yields ( $\mathrm{ml} / 0.5 \mathrm{~g} \mathrm{DM}$ fermented) from forages with less than $7 \% \mathrm{CT}$ in the $\mathrm{DM}$ (Lu, Ku, Lt, Lc and Hc) averaged 0.31 (0-3 h), 0.57 (3-13 h) and declined to 0.41 from $13-24 \mathrm{~h}$. Comparable values for forages containing higher CT concentrations were $0.16,0.19$ and 0.28 for the respective times.

Although there appeared to be a general inverse relationship between CT concentration and methane production at $24 \mathrm{~h}$ (Figure 2 ) the high values for $\mathrm{Hc}$ suggest other factors could have a significant impact on methanogenesis.

Volatile fatty acid concentrations were measured at $24 \mathrm{~h}$ from incubations of Lotus species and Lu. The total yield (Table 3) ranged from $122.4(\mathrm{Lp})$ to $347.6(\mathrm{Lu})$ $\mathrm{mg} / \mathrm{g}$ DM. There was a positive correlation between methane and VFA yields for the five forages, suggesting low methane production was accompanied by a low rate of digestion. The molar proportions of VFA were similar for all five forages after $24 \mathrm{~h}$ of incubation, with 0.67 acetate, 0.19 propionate, 0.10 butyrate and 0.04 
Table 3 Methane yields during in vitro incubations of $0.5 \mathrm{~g}$ forage DM and products of fermentation after $24 \mathrm{~h}$.

\begin{tabular}{|c|c|c|c|c|c|c|c|}
\hline Species & $0-3 \mathrm{~h}$ & $\begin{array}{c}\mathrm{ml} \mathrm{CH}_{4} / \mathrm{h} \\
3-13 \mathrm{~h}\end{array}$ & $\overline{13-24 h}$ & $\begin{array}{c}\mathrm{CH}_{4} \\
(\mathrm{mg})\end{array}$ & $\begin{array}{c}24 \mathrm{~h}- \\
\mathrm{CH}_{4} \\
(\% \text { of } \mathrm{GE})\end{array}$ & $\begin{array}{c}\text { net VFA } \\
(\mathrm{mg})\end{array}$ & $\begin{array}{c}\text { in vivo } \\
\mathrm{CH}_{4} \\
\text { (g/kg DMI) }\end{array}$ \\
\hline \multicolumn{8}{|l|}{ Lotus } \\
\hline pedunculatus & 0.11 & 0.21 & 0.26 & 3.9 & 2.4 & 62 & $11.5^{\mathrm{a}}$ \\
\hline cornic. rhiz. & 0.10 & 0.20 & 0.30 & 4.2 & 2.5 & 82 & * \\
\hline corniculatus & 0.18 & 0.39 & 0.45 & 7 & 4.2 & 169 & $17.9^{b}$ \\
\hline tenuis & 0.26 & 0.40 & 0.31 & 6.1 & 3.7 & 138 & * \\
\hline Sulla & 0.47 & 0.71 & 0.39 & 9.4 & 6.0 & * & $17.5-19.9^{a, c}$ \\
\hline D. rectum & 0.27 & 0.16 & 0.27 & 4.1 & 2.5 & * & * \\
\hline Kikuyu & 0.32 & 0.52 & 0.48 & 8.4 & 5.4 & * & $20.7-23.4^{d}$ \\
\hline Lucerne & 0.34 & 0.85 & 0.44 & 10.6 & 6.6 & 174 & $20.6^{a}$ \\
\hline
\end{tabular}

minor VFA (isobutyrate, valerate and isovalerate). The proportion of propionate was higher when Lp was incubated (0.24) compared to other forages $(0.18)$.

\section{Discussion}

Gas measurement from in vitro incubation was straightforward, repeatable and has demonstrated significant differences between treatments that correspond to differences in ash and CT concentrations. Measurement of methane and hydrogen emissions, expressed in terms of substrate DM or GE content provided realistic values after $24 \mathrm{~h}$ of incubation (Table $3)$, when compared to in vivo digestion. For example, emissions (mg/g DM/ 24h) from Lu (21.2), Hc (18.8), and $\mathrm{Ku}(16.8)$ correspond with emissions from sheep (g/kg DMI) fed Lu (20.6) and Hc (17.7) reported by Waghorn et al. (2002). Woodward et al. (2002) reported methane emissions from cows fed Hc to be $19.9 \mathrm{~g} / \mathrm{kg}$ DMI and Ulyatt et al. (2002) suggested 'normal' emissions from sheep and cows grazing kikuyu to be 20.7 and $23.4 \mathrm{~g} / \mathrm{kg}$ DM, respectively.

In vitro methane emissions from Lc and Lp (14 and $7.8 \mathrm{mg} / \mathrm{g} \mathrm{DM}$ ) were lower than values from animal trials. Woodward et al. (2004) reported $19.9 \mathrm{~g} \mathrm{CH}_{4} / \mathrm{kg}$ DMI from cows fed L. corniculatus, whilst Waghorn et al. (2002) measured $11.5 \mathrm{~g} \mathrm{CH}_{4} / \mathrm{kg} \mathrm{DMI}$ from sheep fed L. pedunculatus.

The yield of VFA at $24 \mathrm{~h}$ ranged from about $34 \%$ of forage DM for $\mathrm{Lu}$ and Lc incubations to only $12 \%$ of DM for Lp. The VFA yield from $\mathrm{Lu}$ and $\mathrm{Lc}$ was similar to the $36 \%$ of DM reported by Barrell et al. (2000) from a $24 \mathrm{~h}$ incubation of minced $L$. corniculatus and corresponds to in vivo rumen digestion. For example, if in vivo $\mathrm{DM}$ digestibility for $\mathrm{Lu}$ or $\mathrm{Lc}$ is about $70 \%$ (Wa ghom et al. 2002) and approximately 65\% of DM digestion takes place in the rumen, with about $65 \%$ of digested DM appearing as VFA (remainder to $\mathrm{CO}_{2}$, ammonia etc), then the VFA yield will be about $30 \%$ of the DMI. The high in vitro VFA yields from $\mathrm{Lu}$ and $\mathrm{Lc}$ contrast with the very low VFA synthesis from Lp. When L. pedunculatus was fed as a sole diet to sheep it decreased the rate of rumen digestion, reduced VFA concentrations by $30 \%$ and increased rumen pool size relative to the same diet fed with polyethylene glycol to remove effects of CT (Waghorn et al. 1994). This suggests the CT in Lp does lower VFA production relative to diets containing less CT, but not to the extent indicated by the in vitro data here.

The lower methane production from forages containing over 9\% CT in the DM was probably a consequence of reduced fermentation. There was an inverse relationship between CT concentration and VFA production from Lotus spp. and Lu (adjusted $\mathrm{R}^{2}=0.88, \mathrm{P}=0.017$ ) and a positive relationship between methane and incubation $\mathrm{pH}$ at $24 \mathrm{~h}$ (adjusted $\mathrm{R}^{2}=0.86, \mathrm{P}<0.001$ ). Relationships between methane production and individual forage constituents were not convincing, in part because concentrations of protein, lipid, NDF and NSC (except for $\mathrm{Ku}$ ) were within a narrow range. Correlation were not statistically significant (adjusted $\mathrm{R}^{2}=0.0,0.11,0.16$ and 0.15 , respectively). Methane correlations (adjusted $\mathrm{R}^{2}$ ) with total $\mathrm{CT}$, unbound $\mathrm{CT}$ and ash were $0.49, \mathrm{P}=$ $0.01 ; 0.47, \mathrm{P}=0.012$; and $0.56, \mathrm{P}=0.005$, respectively. Multiple regression suggested that total or unbound CT and ash provided and improved prediction of methane emissions (adjusted $\mathrm{R}^{2}=0.64$ ). There is no obvious explanation for the strong coloration between methane and ash, other than possible elemental requirements for methanogenesis or other rumen microbes involved, such as fibre-degrading microbes.

When in vitro methane data were correlated with in vivo methane production ( $\mathrm{g} / \mathrm{kg} \mathrm{DMI})$ by sheep fed $L$. pedunculatus (11.5), Lu (20.6), Hc (17.5) (Wa ghom et al. 2002), $\mathrm{Ku}$ (20.7) (Ulyatt et al. 2002) and adjusted emissions from cattle fed L. corniculatus (17.9) (Woodward et al. 2004), Hc (17.5) (Woodward et al. 2002) and $\mathrm{Ku}$ (21.0) (Ulyatt et al. 2002) there was a positive correlation between $24 \mathrm{~h}$ in vitro and in vivo 
emissions (adjusted $\mathrm{R}^{2}=0.62 ; \mathrm{P}=0.035$ ). The animal methane emission $(\mathrm{Y})$ was $0.600 \mathrm{X}+8.33$ where ' $\mathrm{X}$ ' is the in vitro methane production at $24 \mathrm{~h}$ and all values were given the units $\mathrm{g} \mathrm{CH}_{4} / \mathrm{kg}$ DMI. The adjustments made to cow data were a $10 \%$ reduction in $\mathrm{CH}_{4} / \mathrm{kg}$ DMI, based on inventory estimates (NZ Climate Change Office 2003).

In vitro incubations (Ungerfeld et al. 2005) can amplify effects of methanogenic inhibitors (e.g. oils) relative to in vivo measurements (Machmüller et al. 2000), presumably because in vivo fermentation has potential to ameliorate effects of toxic substances and the closed incubations used here may have affected a slower digestion of forages with high concentrations of CT. However the $13 \%$ reduction in methane emissions per DMI attributed to CT from cows fed L. corniculatus with $2.6 \% \mathrm{CT}$ in the DM and an $11 \%$ increase in milk solids production (Woodward et al. 2004) could not have been associated with reduced forage digestion. Any reduction in rate or extent of digestion, associated with a methane inhibitor will be counterproductive, irrespective of methane emissions.

In summary, the in vitro technique is able to give values that are comparable to in vivo measurements in NZ. The observed reduction in in vitro methane emissions from forages containing $\mathrm{CT}$ can be attributed to effects of CT, or possibly ash content of the forage. The future focus of this research is to evaluate a broad selection of forages grazed by ruminants in NZ pastures for methane emissions using the in vitro technique described here.

\section{ACKNOWLEDGEMENTS}

Funding was provided by the Pastoral Green House Gases Research Consortium (PGgRc) of New Zealand. The PGgRc is a joint programme between the New Zealand pastoral agriculture industry and the New Zealand Foundation for Research Science and Technology.

\section{REFERENCES}

Attwood, G.T.; Klieve, A.V.; Ouw erkerk, D.; Patel, B.K.C. 1998. Ammonia"hyper producing bacteria from New Zealand ruminants. Applied Environmental Microbiology 64: 1796-1804.

Barrell, L.G.; Burke, J.L.; Waghorn, G.C.; Attwood, G.T.; Brookes, I.M. 2000. Preparation of fresh forages for incubation and prediction of nutritive value. Proceedings of the New Zealand Society of Animal Production 60. 5-8.

Corson, D.C.; Waghorn, G.C.; Ulyatt, M.J.; Lee, J. 1999. NIRS: Forage analysis and livestock feeding. Proceedings of the New Zealand Grassland Association 61: 127-132.
GenStat (2005) GenStat for Windows. Release 8.0. Eighth Edition. VSN International Ltd., Oxford

Johnson, K.A. and Johnson, D.E. 1995. Methane emissions from cattle. Journal of Animal Science 73: 2483-2492.

Lassey, K.R.; Walker, C.F.; McMillan, A.M.S.; Ulyatt, M.J. 2001. On the performance of SF6 permentation tubes used in determining methane emissions from grazing livestock. Chemosphere Global Change Science 3: 367-376.

Machmüller, A.; Ossowski, D.A.; Kreuzer, M. 2000. Comparative evaluation of the effects of coconut oil, oilseeds and crystalline fat on methane release, digestion and energy balance in lambs. Animal Feed Science and Technology 85: 41-60.

New Zealand Climate Change Office 2003. National inventory report. Climate change. New Zealand Climate Change Office, Wellington.

O'Hara, P.; Freney, J.; Ulyatt, M. 2003. Abatement of agricultural non-carbon dioxide greenhouse gas emissions: A study of research requirements. Report prepared for the Ministry of Agriculture and Forestry on behalf of the Convenor, Ministerial Group on Climate Change, the Minister of Agriculture and the Primary Industries Council.

Tavendale, M.H.; Meagher, L.P.; Pacheco, D.; Walker, N.; Attwood, G.T.; Sivakumaran, S. 2005. Methane production from in vitro rumen incubations with Lotus pedunculatus and Medicago sativa and effects of extractable condensed tannin fractions on methanogenesis. Animal Feed Science and Technology: in press.

Terrill, T.H.; Rowan, A.M.; Douglas, G.B.; Barry, T.N. 1992. Determination of extractable and bound condensed tannin concentrations in forage plants, protein concentrate meals and cereal grains. Journal of the Science of Food and Agriculture 58: 321-329.

Ulyatt, M. J.; Lassey, K.R.; Shelton, I.D.; Walker, C.F. 2002. Methane emission from dairy cows and weather sheep fed subtropical grass-dominant pastures in midsummer in New Zealand. New Zealand Journal of Agricultural Research 45: 227234.

Ungerfeld, E.M.; Rust, S.R.; Burnett, R. J.; Yokoyama, M. T.; Wang, J. K. 2005. Effects of two lipids on in vitro ruminal methane production. Animal Feed Science and Technology 119: 179-185.

Waghorn, G.C.; Shelton, I.D.; McNabb, W.C. 1994. Effects of condensed tannins in Lotus pedunculatus on its nutritive value for sheep. Non-nitrogenous aspects. Journal of Agricultural Science, Cambridge 123: 99-107.

Waghorn, G.C.; Tavendale, M.H.; Woodfield, D.R. 2002. Methanogenesis from forages fed to sheep. 
Proceedings of the New Zealand Grassland Association 64: 167-171.

Woodward, S.L.; Waghorn, G.C.; Lassey, K.R.; Laboyrie, P.G. 2002. Does feeding sulla (Hedysaarum coronarium) reduce methane emissions from dairy cows? Proceedings of the New
Zealand Society of Animal Production 62:227-230. Woodward, S.L.; Waghom, G.C.; Laboyrie P.G. 2004. Condensed tannins in birdsfoot trefoil (Lotus corniculatus) reduce methane emissions from dairy cows. Proceedings of the New Zealand Society of Animal Production 64: 160-164. 